\title{
THE EFFECTIVENESS OF ZUMBA KIDS IMPLEMENTATION INTO PHYSICAL EDUCATION OF ELEMENTARY SCHOOL PUPILS
}

\author{
Olga Rymar \\ Lviv State University of Physical Culture named after Ivan Bobersky, Ukraine \\ Nataliya Sorokolit \\ Lviv State University of Physical Culture named after Ivan Bobersky, Ukraine \\ Alla Solovey \\ Lviv State University of Physical Culture named after Ivan Bobersky, Ukraine \\ Marta Yaroshyk \\ Lviv State University of Physical Culture named after Ivan Bobersky, Ukraine
}

\section{Olena Khanikiants}

Lviv State University of Physical Culture named after Ivan Bobersky, Ukraine

\begin{abstract}
The demand to improve physical education process of elementary school pupils by the tools of innovative dancing fitness branch - Zumba Kids is described in the article. Positive changes in dynamics among children have occurred in indicators of functional and physical preparation in conditions of the experiment. The goal of the work is the optimization process of physical education of elementary school pupils by Zumba Kids tools. There were investigated children's physical development, functional and physical preparation and experimentally was checked the effectiveness of the implementation program of Zumba Kids tolls into process of physical education. There were 54 participants, 26 among them are boys and 28 are girls (the children's age is 9 years old). The methods of the research are theoretical analysis and literature sources generalization; physiological research methods; pedagogical observation (passing of control standards); pedagogical experiment and mathematical statistics methods. There are presented and scientifically justified the program of implementing Zumba Kids tools into physical education lessons of elementary school pupils. The content of the program consists of the synthesis of energetic modern dances with aerobics, fitness exercises, stretching and also exercises for breathing exercises and muscle relaxation. The elaborated program is realized in the educational process and proved its effectiveness. The results of investigation have shown its positive influence on the functional and physical preparation of elementary school pupils. It was proved by mathematical statistics methods.
\end{abstract}

Keywords: elementary school pupils, physical education, Zumba kids. 


\section{Introduction}

In conditions of reforming of education system in Ukraine rises the issue of changing of physical education, beginnings from younger school age. The basis of health, comprehensive physical preparation and harmonized physical development are forming in this age (Bulatova \& Usachov, 2008).

The optimization of physical education of elementary school pupils connected as with strategical task to improve education quality, so with low indicators of health, motor activity and motivation towards physical education classes. In accordance with this, the need to make few corrections into the content, physical education organization of younger pupils and into improvement of educational process, applying innovative tools of motor activity become pretty obvious.

One of possible ways to improve physical education of elementary school pupils is to elaborate and apply innovative technologies. Particularly, it is the implementation of different fitness types into the system of school physical education, that would promote renovation of physical education classes for younger pupils.

There have been appearing fitness technologies in the physical education practice in last years, that are recommended to implement into physical education of younger school age pupils as far as they are oriented to increase physical preparation level, interest towards physical education trainings, they promote physical development, health healing, prevention of different illnesses, forming of personality culture and picture about healthy lifestyle (Starchenko, 2014). Some aspects of theoretical and methodologic implementation of innovative fitness programs into educational process of preschoolers and pupils are shown in the domestic and foreign scientists' works (Hawley \& Franks, 2000; Weinberg \& Gould, 2003; Zhdanova, Chekhovska, \& Bakhovskiy, 2016).

The authors (Chuprun, 2018; Domene, Moir Pummell, \& Easton, 2016; Perez, Robinson, \& Herlong, 2011) have determined the innovative fitness version - Zumba Fitness, created on the basis of popular Latina and other international dance styles. General rhythms and changeable tempos of Zumba Fitness allow to heal musculoskeletal system, cardiovascular, breathing and nervous human systems. It helps to increase level of motor skills and to prevent different illnesses. Emotionality of Zumba fitness is explained not only by music that creates positive mood but also by the desire to follow movements of group participants, the opportunity to demonstrate well-developed movements, to get satisfaction from lessons, that emotionally inspire and raise interest towards classes.

There were defined different variations of Zumba Fitness by scientists (Chuprun, 2018; Domene et al., 2016). These variations are Zumba Basis 
(classic) - for youth and adult people; Zumba Gold - for old people, exercises are characterized by low intensity and decreased tempo; Zumba Sentao exercises performed sitting on the chair; Zumba Toning - performed with dumbbells; Zumba Kids - for 4-12 years old children; Aqua Zumba - exercises performed in water.

Zumba Kids lessons are quite different from classes with adults according to its intensity, load volume, the set of dancing elements and music rhythm. The program content has choreography and dance basics, skipping difficult connection and extra sharp movements.

However, the analysis of literature sources states that the question of implementing Zumba Kids into physical education is not investigated enough by domestic scientists, as far as we have noticed lack of detailed researches and methodic developments according to the issue. That is why, we believe, that implementation of Zumba Kids program into physical education lessons for younger pupils is a relevant problematic.

The goal of the work is the optimization process of physical education of elementary school pupils by Zumba Kids tools.

\section{Materials and Methods}

The research was performed during the period 2018-2019 years. The level of physical development, functional and physical preparation of children has been investigated in the work and experimentally proved the effectiveness of Zumba Kids program in physical education. The experiment was taken by 54 kids in total, among them are 26 boys and 28 girls. The age of all kids in the beginning of the experiment was 9 years old.

In order to reach the goals such methods of research were used:

- $\quad$ theoretical analysis and generalization of literature sources;

- $\quad$ physiologic research methods (to determine cardio-respiratory level of children's functional condition: the pulse of real calm (beats/minute) measure in sitting position in 10 seconds; pulse of relative calm (beats/minute) - measure right after standing up; the difference in pulse; keeping breath during breathing in (sec) - Stange test; keeping breath during breathing out (sec) - Genchi test;

- $\quad$ pedagogical observation after difficult orientation norms (30 m run, sit-ups test in $30 \mathrm{sec}$, long jump from place, sit and reach test, shuttle run $4 \times 9 \mathrm{~m}$ ). The norms passing is performed during physical education lessons in school. The results are written down into protocols;

- $\quad$ pedagogical experiment; 
- $\quad$ mathematical statistics methods.

\section{Results of Research}

The traditional system of physical education become less effective in the questions of health healing, increasing level of pupils' productiveness and requires to update in structure and content.

The implementation of innovative types of motor activity, in particular fitness programs into physical education lessons, promote optimization and modernization of physical education in the educational establishments. Innovative lessons of physical education lessons can increase its emotional component, general and motor intensity of lessons. In the result, the general effectiveness of studying is going to increase as well.

In order to realize the investigating idea, the most attractive, interesting and emotional dancing fitness program Zumba Kids was chosen. It is based on Latina and world modern rhythms. The basis of this direction of aerobic loading are rhythmic movements, that are performed under the music, simplified version of salsa, merengue, cumbia and reggaeton (with mamba, rumba, flamenco and calypso elements). During Zumba Kids is supposed to perform special set of exercises (mini fitness dancing), elaborated specially for all muscle groups. In case of multiple repeat with different rhythms, there appear muscle load and increase of indicators of functional condition and physical preparation. The important specifics of such program is the situation that music rhythm is changing consistently, that is why organism gets load of different level of intensity, without exhausting of central nervous system (Zhdanova, Chekhovska, \& Bakhovskiy, 2016).

It worth mentioning that Zumba Kids lessons are quite simplified, comparing with classic Zumba sessions and characterized with lower intensity and load volume, including different choreographic and dancing exercises, that are adapted to specifics of children's organism, skipping difficult connections and sharp movements.

The program is elaborated for 3 months (36 lessons) and is divided into 2 stages: preparation (6 lessons -4 weeks) and main (30 lessons -10 weeks).

The task of the preparation stage is to get children acquainted with different definitions of Zumba Kids; teach them to perform basic movements, steps, counts, that are performed under musical accompaniment and to teach sustain realized interest towards physical exercises.

The task of the main stage is to improve level of physical development, functional and physical children's preparation applying Zumba Kids lessons, that consist of choreographic and dancing exercises. Its intensity is regulated by music accompaniment, that is directed on strengthen of musculoskeletal system, cardiovascular and breathing system, on improvement of physical preparation 
level, applying Zumba Kids lessons, that facilitate power development, flexibility, endurance and skills coordination.

The program consists of the mix of energetic modern dances connected with aerobics and fitness exercises. Major muscle groups, especially lower body part were loaded during the lessons. There also has been corrected children's posture. A lot of attention was dedicated towards strengthening of muscular corset, whose function is holding the spine. Accordingly, the performing of complex of exercises, that are directed on the development of core muscle (abdominal press) and back power, was provided by the program. The music component consists of rhythms from Latin America, India, Argentina, Spain, Africa and popular worlds' hits. Each lesson includes three parts: preparation part of the lesson is about using of dancing movements under music accompaniment in due to prepare the body before the main part of the lesson and also to prevent posture problems. The music tempo in the preparation part is mostly moderate (60-90 music accents/minute). The main part of the lesson includes 2 blocks: learning of new dancing elements and dancing part (the very dancing), that consists of 3 fitness dances, that are learning and improved each month. Dancing movements are accompanied with different music temps: slow (40-60 music accents/minute), average (90-120 music accents/minute) and high (fast) (130-160 music accents/ minute). This was directed on forming motor skills, rhythm feeling, increase of the level of physical development, functional and physical preparation. The closing part includes stretching and exercises to restore breath and relax muscles. The music tempo in the closing part is generally slow (40-60 music accents/minute).

The effectiveness checkup of the program Zumba kids is performed on the basis of comparison of stated and forming research stages.

Table 1 Indicators of functioning of cardiovascular system of pupils from control and experimental groups

\begin{tabular}{|c|l|c|c|c|c|c|}
\hline \multirow{2}{*}{$№$} & \multicolumn{1}{|c|}{ Indicators } & \multicolumn{2}{|c|}{$\begin{array}{c}\text { Before the } \\
\text { experiment }\end{array}$} & \multicolumn{2}{c|}{ After the experiment } & \multirow{2}{*}{$\mathrm{p}$} \\
\cline { 3 - 6 } & & CG & EG & KG & EG & \\
\hline 1. & $\begin{array}{l}\text { Pulse in sitting } \\
\text { positions(beats/minute) }\end{array}$ & 88,7 & 88,2 & 86,8 & 84,0 & $\mathrm{p} \leq 0,05$ \\
\hline 2. & $\begin{array}{l}\text { Pulse in standing } \\
\text { position(beats/minute) }\end{array}$ & 103,5 & 103,1 & 99,6 & 96,5 & $\mathrm{p} \leq 0,05$ \\
\hline 3. & $\begin{array}{l}\text { The pulse difference } \\
\text { (beats/minute) }\end{array}$ & 14,8 & 14,9 & 12,8 & 12,5 & $\mathrm{p} \geq 0,05$ \\
\hline 4. & Stange test (sec) & 20,4 & 20,3 & 23,2 & 26,4 & $\mathrm{p} \leq 0,05$ \\
\hline 5. & Genchi test (sec) & 10,2 & 9,9 & 11,6 & 13,5 & $\mathrm{p} \leq 0,05$ \\
\hline
\end{tabular}

$(n=54)$ 
There was determined the influence of proposed program on the improvement of functional and physical preparation in the process of the experiment. There was performed general checkup of the results of forming experiment and determined the reliability of given data.

The high level of statistical relevance (in the range from $\mathrm{p} \leq 0,05$ to 0,01 ) characterize changes of indicators of cardiovascular system (Table 1).

It also worth mentioning that that all indicators of cardiovascular system have improved among children from the EG and CG, that is explained by children's body biological development. The difference between pulse in sitting position and standing has improved, but its indicator is not reliable $(\mathrm{p} \geq 0,05)$. It represents natural specifics of 9-years old children. All other indicators got reliable improvements of the result in the experimental group $(\mathrm{p} \leq 0,05)$. Thus, the results of pulse in sitting position has improved among children from the EG by 4,2 beats/minute and in the CG by 1,9 beats/minute; pulse in standing position by 6,6 beats/minute and 3,9 beats/minute respectively.

The pulse improvement among children from the EG is due to as physiologic children's body development so implementation a huge volume of choreographic and dancing exercises under different variations of music tempos into physical education lessons. It has actual positive influence on cardiovascular and breathing system. The significant improvement of the results in the experiments group with its reliable difference with the control group $(p \leq 0,05)$ is observed in the Genchi and Stange tests. The result among pupils from the experimental group in the Stange test has increased by 6,1 sec and in Genchi test by 3,6 sec. In the same time, the analogic test among children from the control group has shown that improvement reaches 2,8 sec and 1,4 sec respectively.

Table 2 The indicators of physical preparation of students from control and experimental groups

\begin{tabular}{|c|c|c|c|c|c|}
\hline \multirow{2}{*}{ Indicators } & \multicolumn{2}{|c|}{$\begin{array}{c}\text { Before the } \\
\text { experiment }\end{array}$} & \multicolumn{2}{c|}{$\begin{array}{c}\text { After the } \\
\text { experiment }\end{array}$} & \multirow{2}{*}{$\mathrm{p}$} \\
\cline { 2 - 5 } & CG & EG & CG & EG & \\
\hline 30 m run (sec) & 6,51 & 6,48 & 6,34 & 5,61 & $\mathrm{p} \leq 0,05$ \\
\hline Long jump from place (cm) & 98,1 & 98,7 & 106,2 & 117,5 & $\mathrm{p} \leq 0,05$ \\
\hline Sit-ups in 30 sec. (number of times) & 13,6 & 13,7 & 16,0 & 25,4 & $\mathrm{p} \leq 0,05$ \\
\hline Sit and reach (cm) & 7,8 & 7,9 & 8,3 & 14,1 & $\mathrm{p} \leq 0,05$ \\
\hline Shuttle sun 4x9m (sec) & 12,13 & 12,18 & 11,94 & 10,63 & $\mathrm{p} \leq 0,05$ \\
\hline
\end{tabular}

$(n=54)$

The comparative analysis of the dynamics of physical preparation of children form $4^{\text {th }}$ experimental and control group allows to determine high level of reliability $\mathrm{p}<0,05$ (Table 2 ). 
The digest increase in results has shown 9-years-old children in the speed development that is characterized by test exercise "30 m run" and agility in "Shuttle run $4 \times 9 \mathrm{~m}$ ". Thus, in the test exercise " $30 \mathrm{~m}$ run" the indicator has increased from 6,51 sec to 6,34 sec. However, we have noticed more significant increase among children from the EG - from $6.48 \mathrm{sec}$ to 5,61 sec. The indicator in the test exercise "Shuttle run $4 \times 9 \mathrm{~m}$ " among pupils from the CG has increased from 12,13 sec to 11,94 sec and among pupils from the EG - from 12,18 sec to $10,63 \mathrm{sec}$. Such improvement of results among children from the EG was resulted by the implementation of a significant number of dancing exercises into classes. The big groups of muscles of lower body part was loaded during these dancing exercises.

The increase in results was occurred also in the test exercise "Sit-ups". Thus, in the CG the indicator has increased from 13,6 times to 16,0 times. From the contrary, in the EG we have noticed more significant increase in result, particularly from 13,7 times to 25,4 times. Such major improvement of results among children from the EG was caused by purposeful implementation of special fitness exercises into classes. These exercises are directed on forming of muscular corset with purpose to prevent and to correct posture defects.

The indicator in the test exercise "Sit and reach" has significantly grown among pupils from the EG - from 7,9 cm to $14,1 \mathrm{~cm}$. The improvement of these indicators was resulted by implementation of stretching and exercises to relax muscles into the closing part of lessons. However, no significant changes have been found out among pupils from the CG.

The analysis of result, we have got, allows to determine that indicator change of coordination, speed skills and flexibility among pupils from the EG, comparing with pupils from the CG, are characterized with high level of statistical reliability $(\mathrm{p}<0,05)$. It proves previous scientists researches (Krutsevych, 2016; Moskalenko, 2018; Pangelova, 2017) about sensitive period of development of such qualities among pupils of this age.

The significant increase in results got pupils from the CG and the EG in the development of body muscles that is characterized by test exercise "Body lifting from lying position". In our opinion, such fact is due to the situation that all exercises are included in the school program from physical education, as required exercises and primary education teachers give enough attention towards it during the physical education lessons and in home tasks. However, the increase among pupils from the EG was more intense that prove the reliability of results difference among pupils from the CG and the EG that reflects Student's $\mathrm{t}$-criteria $\mathrm{p}<0,05$. The common tendency is noticed in the test exercise "Long jump from place" in favor to the EG.

To conclude, after the experiment the difference between indicators among pupils from the EG and the CG was as follows: $30 \mathrm{~m}$ run - 0,7 sec; body slope 
from sitting position $-5,7 \mathrm{~cm}$; long jump from place $-10,7 \mathrm{~cm}$; shuttle run $4 \times 9 m-1,36$ sec; body lifting from the lying position - in 9,3 times. Those children, studying according to the experimental program have shown reliably higher results $(p<0,05)$ in all types of challenges, comparing to the control group.

\section{Discussion}

The development of modern physical education is characterized with education modernization, its transformation with the goal to increase effectiveness on the basis of applying of new types of motor activity (Beliak, Grybovska, \& Muzyka 2018; Bulatova \& Usachov, 2008; Starchenko, 2014). The main task of specialists is to determine modern approach towards studying process. In other words, the goal is to implement innovative tools of physical education and implement them into classes (Bodnar, Rymar, Solovey, \& Datskiv, 2015; Khouli \& Frenke, 2004; Sorokolit, Shyan, Lukjanchenko, \& Turchyk, 2017).

The optimization of physical education classes can be observed through the implementation of dancing and fitness program Zumba Kids, that will promote as renovation of physical education classes, so will promote health healing, increase of the level of functional and physical preparation.

The results of our research were confirmed and supplemented by scientists' well-known developments from this particular sphere (Bodnar, 2016; Moskalenko, 2018; Pangelova, 2017; Starchenko, 2014; Zhdanova et al., 2016).

In the result of implementation of author program, including Zumba Kids, has credibly improved indicators of functional preparation of younger pupils in the experimental group. The results we have got prove the positive impact of the elaborated methodic.

We have observed the improvement in the indicators of physical preparation in experimental and control groups after the experiment that is a consequence of biological development of children's organism (Bodnarchuk, Rymar, \& Solovey, 2018; Butenko, Goncharova, \& Saienko, 2017; Sarkauskiene, Noble, \& Kardeliene, 2019) and directed pedagogical influence.

The implementation of Zumba Kids into physical education is promote improvement of agility, speed, power-speed and flexibility indicators. It is proved by much higher results of physical preparation among pupils from the experimental group.

Thus, our author program that includes Zumba Kids in the physical education lessons allows to solve the whole variety of tasks from physical education with younger-school-age pupils. In particular, it is about health healing, providing of balanced body development, improvement of functional 
indicators, increase of level of physical preparation, including favorable periods of the development of physical qualities and increase of the interest level towards lessons of motor activity.

\section{Conclusion}

The performing of the pedagogical experiment from the implementation into practice author program, applying Zumba Kids allows to make conclusions about its benefits, comparing with traditional program. The positive changes of indicators among pupils from the EG have more significant character, comparing with indicators among pupils from the CG.

The checkup of the effectiveness of experimental-investigation work has shown positive influence of suggested methodic according facilitating of functional preparation of younger pupils. We have noticed that after the experiment such positive changes have occurred in indicators of cardiovascular system activity among pupils from the EG: indicators of heart rate have decreased by 4,76-6,40\%, Stange tests results have increased by 30,50\%; Genchi tests by $36,36 \%$.

The dynamics of physical preparation indicators among the EG pupils is heterochronous in due to general biologic patterns of growth and development of children's body (Bodnar, Petryshyn, Solovey, \& Rymar, 2016; Krutsevych \& Bezverhniya, 2010; Moskalenko, 2009). The highest increase in results occurred in development of coordination an speed skills among younger pupils. The change of dynamics of these indicators among pupils from the EG, comparing with pupils from the CG is characterized by high level of statistical reliability $(\mathrm{p}<0,05)$.

\section{References}

Beliak, Y., Grybovska, I. \& Muzyka, F. (2018). The theoretical-mathematical basis of the healing fitness. Lviv: LDUFK.

Bodnar, I., Petryshyn, Y., Solovey, A., \& Rymar, O. (2016). Health complaints and wellbeing complaints among secondary school children. Journal of physical education and sport, 16(3), 905-909.

Bodnar, I., Rymar, O., Solovey, A., \& Datskiv, P. (2015). Objective criteria for determination of functional-reserve opportunities of average school age pupils. Pedagogics, psychology and medical-biological problems of the physical education, 11, 11-19.

Bodnarchuk, O., Rymar, O., \& Solovey, A. (2018). Interaction of school and family in physical education of first grade pupils. Journal of physical education and sport, 18(2), $1092-1098$.

Bulatova, M., \& Usachov, U. (2008). The modern physical-healing technologies in the physical education. The theory and methodic of physical education, 2, 320-353. 
Butenko, H., Goncharova, N., \& Saienko, V. (2017). Physical condition of primary school children in school year dynamics Department of Theory and Method Published. Journal of Physical Education and Sport, 2, 543-549.

Chuprun, N.F. (2018). Place Zumba in the physical education of student youth. The journal of CHernigiv national pedagogical university. Series: Pedagogical sciences. Physical education and sport, 154(1), 193-196. Retrieved from http://nbuv.gov.ua/ UJRN/VchdpuPN_2018_154(1)_44.

Domene, P., Moir, H., Pummell, E., \& Easton, Ch. (2016). Salsa dance and Zumba Fitness: Acute responses during community - based classes. Journal of Sport and Health Science, 190-196.

Hawley, E., \& Franks, B. (2000). Health-Related Aerobics. Kyiv.

Khouli, E., \& Frenke, B. (2004). The instructor guide of healing fitness. Kyiv: Olympic literature.

Krutsevych, T., \& Bezverhniya, G. (2010). Recreation in the physical education of different society groups. Kyiv: Olympic literature.

Moskalenko, N. V. (2018). Construction of rational regimes in motor activity of children aged 3-4 years in pre-school educational institutions of various types. Pedagogics, psychology, medical-biological problems of physical training and sports, 5, 265-271. http://orcid.org/0000-0001-9162-5206 .

Moskalenko, N.V. (2009). The theoretical-methodical basis of innovative technologies in the system of physical education of elementary school children ("Physical culture, physical education of different society groups"): autoref. diss. Of the doctor of science of physical education and sport. Kyiv.

Pangelova, N. (2017). The modern approaches to organizing physical culture and health related work with lower grades pupils of a comprehensive rural school. Theory and methods of physical education and sports, 3, 93-97. Retrieved from http://nbuv.gov.ua/UJRN/TMFVS_2017_3_16.

Perez, B., Robinson, P., \& Herlong, K. (2011). The guide for instructor of fitness program "Zumba". Florida, USA.

Sarkauskiene, A., Noble, B., \& Kardeliene, L. (2019). Non - formal physical education influence on health related physical fitness of children. Society. Integration. Education. Proceedings of the International Scientific Conference, IV, 252-267.

Sorokolit, N., Shyan, O., Lukjanchenko, M., \& Turchyk, I. (2017). Improvement of 5-9th Grades Schoolchildren Physical Education in Ukraine by Using Variable Modules Curriculum. Journal of Physical Education and Sport, 17(4), 2110-2115.

Starchenko, A.U. (2014). The children fitness as one of the effective tools of health healing and physical education of pre-school age children. Pedagogical sciences: theory, history, innovative technologies, 2(36), 177-184.

Weinberg, R., \& Gould, D. (2003). Foundations of sport \& exercise psychology: third edition. Human Kinetics.

Zhdanova, O., Chekhovska, L., \& Bakhovskiy, L. (2016). New tendencies of the fitness development. The material from the X All-Ukrainian Scientific-practical conference with international participation "The problems of activation of recreational-healing activity of society”. Lviv, 204-212. 